American Journal of Pharmaceutical Education 2017; 81 (6) Article 100.

\title{
COMMENTARY
}

\section{Transition and Student Well-being - Why We Need to Start the Conversation}

\author{
Caitlin E. Kulig, $\mathrm{BS}^{\mathrm{a}}$ and Adam M. Persky, $\mathrm{PhD}$, a,b \\ ${ }^{a}$ Eshelman School of Pharmacy, University of North Carolina at Chapel Hill, Chapel Hill, North Carolina \\ ${ }^{\mathrm{b}}$ Associate Editor, American Journal of Pharmaceutical Education, Alexandria, Virginia
}

\begin{abstract}
Every year our pharmacy programs enroll new students. Some of these students will transition smoothly, but others may not transition optimally. This transition issue can have potentially severe mental health consequences and be caused by a multitude of factors. We need to identify these factors, be able to identify at-risk students, and have programs in place to help better support our students' mental health.
\end{abstract}

Keywords: students, depression, anxiety, transition

Moving to a new state - emotionally taxing. Starting at a new school with a new life path - emotionally stressful. Being assigned 40 pages of reading along with three upcoming exams, and almost daily quizzes - emotionally demanding. Trying your best to make friends - emotionally frustrating. Attempting to get more than five hours of sleep and failing while balancing the new life path, schoolwork and all the other life events - almost impossible. Welcome to being a new student pharmacist.

Many students find themselves moving anywhere from a few miles from home to hundreds of miles. These students are away from everything familiar. They all find themselves on the front steps of a new building, where they will spend the next three to six years with the same group of people and, much like high school, all of the subgroups and cliques. The halls of the building are filled with some of the most brilliant students, who also donate their time to many causes outside the classroom. Some of them have hidden time commitments, such as taking care of parents, siblings, children or working just to pay for school. These students are some of the greatest people we have ever had the pleasure to meet. In addition, most student pharmacists were once a big fish in a small pond and now find themselves swimming in a sea of people who all seem to be smarter, more articulate, and more diligent than they are. Are we surprised when some students struggle to adjust, secretly or openly?

Transition issues are not new - though there is little data regarding pharmacy students. Roughly $5 \%$ of medical students experience suicidal thoughts at some point during

Corresponding Author: Adam M. Persky, 2312 Kerr Hall, CB\#7569, Division of Pharmacotherapy and Experimental Therapeutics, Eshelman School of Pharmacy, University of North Carolina at Chapel Hill, Chapel Hill, NC 27599. Tel: 919-966-9104.E-mail: apersky@unc.edu school while about $14 \%$ of medical students experience moderate to severe depression. ${ }^{1}$ This rate of depression is above the average, according to the National Institute of Mental Health's estimates for $18-25$ year olds $(10.3 \%$, as of $2015,9.3 \%$ 2014), who suffer the largest percentage of major depressive disorders. These statistics do not consider mild or moderate depression, anxiety or eating disorders, which also are on the rise. The true impact of this problem is unknown because a major barrier to accurate data is the stigma of depression or anxiety. In an anonymous poll, students were asked whether they had experienced depression during school, and $84 \%$ said that they had. ${ }^{2,3}$ This issue can be even more severe in first-year professional students. A recent study by the Journal of the American Medical Association (JAMA) found that first- and secondyear medical students more often agreed that seeking help for depression would make them feel less intelligent. ${ }^{4}$

So, why should we care about transition issues among pharmacy students? For one, transition issues often lead to depression or anxiety, which is associated with lowered work functioning and impaired productivity. These are crucial in the training years in any health care profession. ${ }^{5}$ Depression is also a recurrent disease, and studies have shown that pharmacists have an increased likelihood of committing suicide. ${ }^{6}$ So, we should care because the mental health of our students is important for their overall health, success, and well-being. But how do we know a student is having an issue?

There is a dearth of research pertaining to transition issues in professional students, especially in pharmacy. Part of this may be due to the abstract nature of transition issues. For example, a question that always comes to mind is how to define a true transition problem. Is it simply progression issues or failures? Is it a lack of social contact or friends? Or is it deeper than just results, such as students not meeting their own expectations or maybe the 


\section{American Journal of Pharmaceutical Education 2017; 81 (6) Article 100.}

expectations of their parents or peers? How can we determine if a transition problem is important and isn't just about grades? If we define a transition problem, can we predict who may be more susceptible?

Transition issues may be lessened if caught early onor even pre-identified. The causes must be identified. Are there factors that may predispose a new student to experiencing future transition problems? Could distance moved from home be a factor? What about the level of parental attachment? Do "helicopter parents" increase the likelihood of issues in the future? How about first-generation students? Or if they are an underrepresented minority? If such factors can be determined, then the hope would be that students at higher risk for experiencing transition issues could be identified and participate in early intervention. But if we can identify people at risk, then what will we do to help?

One thing is clear: More research needs to be done about what drives transition issues in pharmacy and professional health care students. We also need to talk more as a profession about the realities of being human and starting such rigorous professions and careers. It is not enough to simply have an office to help students if students do not come to it. In fact, most students experiencing depression or other mental health issues admit that they would never seek help. Even if students seek assistance, are our faculty and other staff prepared to help? Can we do more to support students' mental health?

Students are the future of our profession, and we need to do our best to invest in them professionally and emotionally. Every student in every pharmacy program in the country has likely heard a speech from their dean or professors about working harder, becoming great, and striving to be the best. However, we cannot help others if we cannot help ourselves. Pharmacy faculty need to be willing to talk to students and start the conversation, to let students know that there is no such thing as "perfect," that issues do arise, and that at the end of every day, we are all human. As the new semester starts, talk to students about what they can expect that first year. Observe behavior, ask how students are doing and, most importantly, do not assume. Be flexible, open, caring, and understanding.

\section{REFERENCES}

1. Beck A, Crain AL, Solberg LI, et al. Severity of depression and magnitude of productivity loss. Ann Fam Med. 2011;9(4):305-311. 2. Batt J. The differential-are you feeling depressed? Medscape, http://boards.medscape.com/forums?128\%40537.JvBcaZijOFo\% 40.2a0571a2\%21 comment=1. Accessed August 14, 2017.

3. Chi K. Disclosures: depression in med school: you're not alone, Medscape, http://www.medscape.com/viewarticle/739527. Accessed Aug 14, 2017.

4. Schwenk TL, Davis L, Wimsatt LA. Depression, stigma and suicidal ideation in medical students. JAMA. 2010;304(11):11811190 .

5. McIntosh WL, Spies E, Stone DM, Lokey CN, Trudeau AT, Bartholow B. Suicide rates by occupation group - 17 states, 2012. MMWR Morb Mortal Wkly. http://www.cdc.gov/mmwr/volumes/65/ $\mathrm{wr} / \mathrm{mm} 6525 \mathrm{a} 1 . \mathrm{htm}$.

6. Burcusa SL, Iacono WG. Risk for recurrence in depression. Clin Psychol Rev. 2007;27(8):959-985. 